\title{
FAUNA EDÁFICA NA DINÂMICA SUCESSIONAL DA MATA ATLÂNTICA EM FLORESTA ESTACIONAL SEMIDECIDUAL NA BACIA DO RIO PARAÍBA DO SUL - RJ
}

\author{
SOIL FAUNA IN SUCCESSIONAL DYNAMICS OF ATLANTIC FOREST IN SEMI-DECIDUOUS \\ SEASONAL FOREST IN THE BASIN OF RIVER 'PARAIIBA DO SUL', RIO DE JANEIRO STATE
}

\author{
Deivid Lopes Machado ${ }^{1}$ Marcos Gervasio Pereira ${ }^{2}$ Maria Elizabeth Fernandes Correia ${ }^{3}$ \\ Anderson Ribeiro Diniz ${ }^{4}$ Carlos Eduardo Gabriel Menezes ${ }^{5}$
}

\begin{abstract}
RESUMO
A fauna edáfica, pela sua diversidade e magnitude das funções que realiza no ambiente solo, pode refletir o estado de funcionamento dos ecossistemas. Neste sentido, este estudo teve como objetivo avaliar a atividade, composição estrutural e diversidade da comunidade da fauna do solo, em diferentes estádios sucessionais da Mata Atlântica, em Pinheiral - RJ. Para tanto, foram estudadas três áreas de Floresta Estacional Semidecidual Submontana em diferentes estádios sucessionais: Floresta em Estádio Inicial (FEI), Floresta em Estádio Médio (FEM) e Floresta em Estádio Avançado (FEA). Em cada área foi demarcada uma parcela de $30 \mathrm{~m} \times 30 \mathrm{~m}$. Para captura dos organismos epígeos da mesofauna e macrofauna, utilizaramse armadilhas do tipo "pitfall-traps", sendo distribuídas, aleatoriamente, 10 armadilhas em cada área. Foram realizadas amostragens em abril e agosto de 2009. A atividade dos organismos (ind arm ${ }^{-1} \mathrm{dia}^{-1}$ ) e os índices ecológicos de riqueza e equidade de Pielou foram calculados a partir da quantificação e identificação dos indivíduos amostrados. A partir da análise dos resultados, contatou-se que o mês de agosto, caracterizado com maior precipitação, influiu diretamente na atividade, composição estrutural e diversidade da fauna do solo. A estrutura populacional foi influenciada pelos estádios sucessionais, sendo que a atividade dos grupos Acari, Araneae, Diptera, Formicidae, Hymenoptera e Isopoda aumentou em função do avanço sucessional. A atividade total e o índice de riqueza média também responderam ao processo de sucessão. $\mathrm{O}$ grupo Entomobryomorpha foi o mais abundante em todas as áreas, sendo o responsável pelas variações do índice de Pielou. De maneira geral, verificaram-se maiores valores da atividade dos grupos, atividade total e riqueza média na FEA, e menores na FEI, confirmando, assim, o potencial uso desses organismos como indicadores da dinâmica sucessional em florestas secundárias.
\end{abstract}

Palavras-chave: sucessão florestal; indicadores edáficos; fauna do solo.

\begin{abstract}
The soil fauna, for its diversity and magnitude of the tasks that it carries out in the soil environment, may reflect the state of the ecosystem functioning. Therefore, this study aimed to evaluate the activity, the structural composition and the diversity of soil fauna community in different successional stages of Atlantic forest, in

1 Engenheiro Florestal, Doutorando em Ciências Florestais na Universidade Estadual Paulista "Júlio de Mesquita Filho", Campus Botucatu, Fazenda Lageado, Rua José Barbosa de Barros, 1780, Rod. Alcides Soares, Km 3, CEP 18610-307, Botucatu (SP), Brasil. deivid.machado@ig.com.br

2 Engenheiro Agrônomo, Dr., Professor Associado IV do Departamento de Solos, Universidade Federal Rural do Rio de Janeiro, BR 465, Km 7, CEP 23890-000, Seropédica (RJ), Brasil. Bolsista do CNPq. mgervasiopereira01@gmail.com

3 Bióloga, Drª., Pesquisadora da Embrapa Agrobiologia, BR 465, Km 7, CEP 23890-000, Seropédica (RJ), Brasil. ecorreia@cnpab.embrapa.br

4 Engenheiro Florestal, Doutorando em Ciência do Solo na Universidade Federal Rural do Rio de Janeiro, BR 465, Km 7, CEP 23890-000, Seropédica (RJ), Brasil. andersonribeiro02@gmail.com

5 Licenciado em Ciências Agrícolas, Dr., Professor do Instituto Federal de Educação, Ciência e Tecnologia do Rio de Janeiro, Campus Nilo Peçanha, Rua José Breves, 550, CEP 27197-000, Pinheiral (RJ), Brasil. ceduardogm@uol.com.br
\end{abstract}

Recebido para publicação em 5/06/2011 e aceito em 17/06/2013

Ci. Fl., v. 25, n. 1, jan.-mar., 2015 
Pinheiral, RJ state. Thus, three areas of lower montane semi-deciduous forest in different succession stages were studied: Forest in initial stage (FIS), Forest in intermediate stage (FINS) and Forest in advanced stage (FAS). In each area, it was demarcated a plot of $30 \mathrm{~m}$ x $30 \mathrm{~m}$. To capture the epigean organisms, mesofauna and macrofauna, 'pitfall-traps' were used, being distributed, randomly, 10 traps in each area. The samples were taken in April and August 2009. The activity of organisms $\left(\operatorname{arm~ind~}^{-1}\right.$ day $\left.^{-1}\right)$ and ecological index of the richness and evenness were calculated from the quantification and identification of individuals sampled. From the analysis of the results, it was noticed that August featured higher precipitation and directly influenced the activity, structural composition and diversity of soil fauna. The population structure was influenced by successional stages, and group activity Acari, Araneae, Diptera, Formicidae, Hymenoptera and Isopoda increased with advancing succession. Total activity and average wealth index also responded to the advancement of vegetation. The group Entomobryomorpha was the most abundant in all areas, being responsible for the variations of the index of evenness. In general, there were higher values of group activity, total activity and average wealth in FAS, and lower the FIS, thus confirming the potential use of these organisms as indicators of successional dynamics of secondary forests.

Keywords: forest succession; edaphic indicators; soil fauna.

\section{INTRODUÇÃO}

Nos ecossistemas florestais, a produção e a decomposição da serapilheira constituem o principal meio de acúmulo de matéria orgânica e transferência de nutrientes para o solo, sendo considerados, nesses sistemas, processos fundamentais da ciclagem biogeoquímica (BARLOW et al., 2007). Contudo, a decomposição é um processo essencialmente biológico, em que organismos invertebrados e microrganismos são os principais agentes da desestruturação física e química do material vegetal (LAVELLE et al., 1993). Nesse sentido, a importância da diversidade biológica pode ser vista diretamente, por meio das transformações biogeoquímicas que os organismos desempenham no ambiente do solo, ao atuarem nos processos de fragmentação do material vegetal e, indiretamente, ao estimularem toda a comunidade microbiana (CORREIA e ANDRADE, 2008).

De uma forma geral, todos os organismos da fauna edáfica estão intimamente relacionados com os processos de ciclagem de nutrientes, e do ponto de vista funcional, os organismos associados aos processos de decomposição no sistema serapilheira-solo, chamados de fauna do solo (LAVELLE et al., 1993) ou fauna edáfica, são comumente classificados em 3 grupos principais: microfauna, mesofauna e macrofauna (MELO et al., 2009). A microfauna, que inclui organismos menores que $0,2 \mathrm{~mm}$, como exemplo, os nematoides e os protozoários, atua diretamente na ciclagem de nutrientes, por meio da predação de fungos e bactérias (MOREIRA et al., 2010). Os organismos da mesofauna medem entre 0,2 a $2,0 \mathrm{~mm}$, sendo os representantes mais comuns os colêmbolos e ácaros, atuando como transformadores do material vegetal e micropredadores, contribuindo com papel regulatório na biota do solo (MOREIRA et al., 2010). A macrofauna, que inclui organismos visíveis a olho $\mathrm{nu}(>2,0 \mathrm{~mm})$, é representada por mais de 20 ordens taxonômicas, sendo que os grupos também podem ser classificados conforme sua funcionalidade, em saprófagos, parasitas, predadores e engenheiros do ecossistema (MOREIRA et al., 2010). Os organismos da macrofauna influem tanto na ciclagem de nutrientes, quanto na formação de poros e na agregação do solo. Além disso, agem como controladores biológicos, por meio da predação de outros invertebrados.

Vários são os fatores que podem ter influência na abundância, atividade, composição e diversidade da fauna edáfica, como os edáficos (tipo de solo, minerais predominantes, temperatura, $\mathrm{pH}$, matéria orgânica, umidade, textura e estrutura), os relacionados à vegetação (fisionomia e cobertura), os históricos (especialmente antrópico, mas também geológico), os topográficos (posição fisiográfica, inclinação) e os climáticos (precipitação, temperatura, vento, umidade relativa do ar). Assim, qualquer intervenção, seja antrópica ou natural, pode potencialmente afetar a dinâmica da fauna do solo e, por consequência, as funções ecológicas na qual ela está envolvida (MELO et al., 2009).

Diante de sua diversidade, funções que realizam no ambiente do solo e também a sensibilidade às alterações, o estudo da comunidade edáfica tem sido visto não só como indicador 
de ambientes degradados, mas também de sua restauração (SNYDER e HENDRIX, 2008; GIEBELMAN et al., 2010). Neste sentido, em ecossistemas florestais, a fauna edáfica tem sido alvo de muitos trabalhos de pesquisa, principalmente, como indicadora da recuperação e restauração de áreas florestais perturbadas e degradadas (MORAES, 2005; MAJER et al., 2007; WARDLE et al., 2006; SNYDER e HENDRIX, 2008; LAOSSI et al., 2008; BALL et al., 2009; DAVIS e UTROP, 2010; GIEBELMAN et al., 2010). No entanto, ainda é incipiente o conhecimento da comunidade da fauna do solo em áreas de florestas secundárias e sua relação com o processo sucessional.

Assim, o presente trabalho teve como objetivo caracterizar a comunidade da fauna edáfica, quanto a sua atividade, composição estrutural e diversidade, em diferentes estádios sucessionais da Mata Atlântica, Pinheiral - RJ, em dois meses do ano, abril e agosto.

\section{MATERIAL E MÉTODOS}

\section{Localização e caracterização da área de estudo}

A pesquisa foi realizada no município de Pinheiral, Rio de Janeiro, na região do Médio Paraíba Fluminense, situado na sub-bacia do Ribeirão Cachimbal, que compõe a bacia hidrográfica do rio Paraíba do Sul, localizado entre as latitudes $22^{\circ} 29^{\prime} 03^{\prime \prime} \mathrm{S}$ e $22^{\circ} 35^{\prime} 27^{\prime \prime} \mathrm{S}$ e entre as longitudes

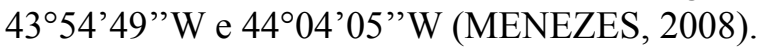

O clima da região, de acordo com a classificação de Köppen, foi identificado de duas formas distintas, em Cwa - clima temperado de inverno seco e verão chuvoso e Am - clima tropical chuvoso com inverno seco (OLIVEIRA, 1998). Dados da antiga Estação Meteorológica do município de Piraí - RJ, apresentados por Oliveira (1998), indicam que a região apresenta precipitação anual em torno de $1300 \mathrm{~mm}$ e temperatura média anual de $21^{\circ} \mathrm{C}$.

A região está inserida no domínio ecológico do Bioma Mata Atlântica, cuja vegetação original denomina-se Floresta Estacional Semidecidual Submontana (IBGE, 1992), característica de zonas de altitudes entre 300 e 800 metros. A vegetação dominante na região é constituída por pastagens, implantadas e espontâneas não manejadas, que se apresentam em diferentes estádios de degradação, nível de uso e/ou abandono, dando origem às demais formas de vegetação da área, como os pastos sujos e as capoeiras em diferentes estádios sucessionais (MENEZES, 2008). Os solos predominantes nas encostas são Argissolos Vermelho-Amarelos, Latossolos VermelhoAmarelos e Cambissolos Háplicos (MENEZES, 2008).

O estudo foi realizado em um fragmento de Floresta Estacional Semidecidual Submontana que possui área aproximada de 190 hectares. Os estádios sucessionais avaliados estão inseridos nesse fragmento, e foram selecionados por Menezes (2008), estudando atributos do solo no Médio Vale do Paraíba do Sul, Pinheiral - RJ. O autor definiu as áreas com base na interpretação de fotografias aéreas e informações históricas de uso das terras, obtidas com antigos moradores do município de Pinheiral - RJ, que residiam e utilizavam as terras na sub-bacia em estudo, entre as décadas de 1950 e 2000 . A partir dessas informações, foi feito o reconhecimento do fragmento in loco, buscando-se definir áreas com diferentes estádios sucessionais, mas sob mesmas condições edafoclimáticas, como posicionamento na encosta (terço superior), face de exposição (sudeste), declividade (entre 40 e 70\%) e classe de solo (Cambissolo Háplico Distrófico típico). Em função dessas características foi delimitada, em cada estádio sucessional, uma parcela de $50 \mathrm{~m} \times 50 \mathrm{~m}$.

A cobertura vegetal secundária foi classificada em diferentes estádios sucessionais da Mata Atlântica (CONAMA 006/94): Floresta secundária em Estádio Inicial (FEI), com aproximadamente 20 anos de sucessão; Floresta secundária em Estádio Médio (FEM), com aproximadamente 25 anos de sucessão; e Floresta secundária em Estádio Avançado (FEA), com aproximadamente 65 anos de sucessão. A seguir são apresentados o histórico e a caracterização das áreas estudadas, baseados em Menezes (2008).

- FEI: localiza-se no terço superior da encosta, a altitude de $466,7 \mathrm{~m}$. A vegetação verificada até 1990 era composta por pastagem formada por vegetação espontânea, manejada por simples roçada anual e queimadas eventuais. A partir desses eventos, a área foi ocupada por pequenos agricultores que, em função da dificuldade de acesso à mesma, apenas a cercaram, o que proporcionou o início da regeneração natural de capoeira. A área apresenta fisionomia herbáceo-arbustiva com predomínio de espécies heliófilas, poucas espécies lenhosas (menos que vinte por hectare) com reduzidos diâmetros a altura do peito (DAP), média 
menor que $5 \mathrm{~cm}$, e altura total média menor que $5 \mathrm{~m}$. Foram identificadas sete espécies, divididas em cinco famílias, sendo estas Annonaceae, Melastomataceae, Siparunaceae, Thelypteridaceae e Urticaceae.

- FEM: situa-se no terço superior da encosta, na mesma altitude que a FEI. A área se encontrava até 1985, sob cobertura de pasto sujo, com formação inicial de capoeira, sendo também protegida por cerca, o que permitiu o desenvolvimento sucessional. Apresenta fisionomia arbustivo-arbórea, com início de estratificação e ocorrem espécies de sombra. Foram identificadas 10 espécies, com indivíduos com DAP entre 5 e $10 \mathrm{~cm}$, e altura média de $8 \mathrm{~m}$. As famílias verificadas nesse estádio sucessional foram Anacardiaceae, Lecythidaceae, Melastomataceae, Moraceae, Myrsinaceae, Myrtaceae, Rubiaceae, Sapindaceae, Siparunaceae e Urticaceae.

- FEA: localiza-se a altitude de 521,9 m. Pelos relatos de moradores, essa área é considerada a mais antiga da porção inferior da sub-bacia, sendo a cobertura florestal formada após a decadência da cafeicultura na região. A área apresenta fisionomia arbórea, com árvores emergentes, sub-bosque já diferenciado e formado por espécies tolerantes, grande variedade de espécies lenhosas, grande número de indivíduos regenerantes e presença de lianas e epífitas em abundância. Foram encontradas 35 espécies arbóreas, com valores médios de DAP e altura, respectivamente, de $15 \mathrm{~cm}$ e de $17,5 \mathrm{~m}$. As famílias verificadas nesse estádio foram Anacardiaceae, Bignoniaceae, Burseraceae, Fabaceae, Erythroxylaceae, Lauraceae,
Lecythidaceae, Malvaceae, Meliaceae, Moraceae, Myrtaceae, Nyctaginaceae, Polygonaceae, Rubiaceae, Sapindaceae, Siparunaceae, Solanaceae e Urticaceae.

Na Tabela 1 são apresentados os valores de variáveis quantitativas e qualitativas do material vegetal dos três estádios sucessionais estudados, obtidas segundo Machado (2011).

\section{Amostragem da comunidade da fauna do solo}

A mesofauna e macrofauna edáfica, de cada estádio sucessional, foi amostrada, nos limites da parcela de $50 \mathrm{~m} \times 50 \mathrm{~m}$, em uma subparcela de $30 \mathrm{~m}$ x $30 \mathrm{~m}$ (área útil total de $900 \mathrm{~m}^{2}$ ). Esse procedimento se fez necessário para evitar o efeito entre os estádios sucessionais, já que as áreas de FEI e FEM são vizinhas.

Para quantificar e caracterizar a comunidade da fauna foram realizadas duas amostragens, a primeira no intervalo que corresponde à transição entre o final do período chuvoso e início do período seco (abril de 2009) e a segunda no final do período seco e início do período chuvoso (agosto de 2009).

Para a captura dos organismos foram utilizadas armadilhas de queda "pitfall-traps", que consistem em recipientes plásticos com $10 \mathrm{~cm}$ de diâmetro e $10 \mathrm{~cm}$ de altura (AQUINO etal., 2006). Em cada estádio sucessional, nos limites da subparcela, foram distribuídas, aleatoriamente, 10 armadilhas, perfazendo 10 repetições por área. Para instalação das armadilhas, com auxílio da ferramenta "boca de lobo", foram abertos buracos do tamanho da mesma,

TABELA 1: Deposição anual de serapilheira e conteúdo total anual de nutrientes da serapilheira, nas áreas de floresta em estádio inicial (FEI), floresta em estádio médio (FEM) e floresta em estádio avançado (FEA) Pinheiral - RJ.

TABLE 1: Annual deposition of litter and annual total nutrient content of litter, in the areas of forest in initial stage (FIS), forest in intermediate stage (FINS) and forest in advanced stage (FAS), Pinheiral, RJ state.

\begin{tabular}{lccc}
\hline \multirow{2}{*}{ Variáveis quantitativas e qualitativas da serapilheira } & \multicolumn{3}{c}{ Áreas de estudo } \\
\cline { 2 - 4 } & FEI & FEM & FEA \\
\hline Serapilheira $\left(\mathrm{Mg} \mathrm{ha}^{-1}\right)$ & 7,47 & 8,96 & 14,70 \\
$\mathrm{~N}\left(\mathrm{~kg} \mathrm{ha}^{-1} \mathrm{ano}^{-1}\right)$ & 86,79 & 101,69 & 306,85 \\
$\mathrm{P}\left(\mathrm{kg} \mathrm{ha}^{-1} \mathrm{ano}^{-1}\right)$ & 3,50 & 4,22 & 7,94 \\
$\mathrm{~K}\left(\mathrm{~kg} \mathrm{ha}^{-1} \mathrm{ano}^{-1}\right)$ & 41,39 & 53,57 & 67,44 \\
$\mathrm{Ca}\left(\mathrm{kg} \mathrm{ha}^{-1} \mathrm{ano}^{-1}\right)$ & 174,15 & 241,87 & 252,53 \\
$\mathrm{Mg}\left(\mathrm{kg} \mathrm{ha}^{-1} \mathrm{ano}^{-1}\right)$ & 22,45 & 37,57 & 62,84 \\
\hline
\end{tabular}

Fonte: Machado (2011). 
sendo a armadilha acomodada até que sua abertura ficasse nivelada com a superfície do solo. Dentro dos recipientes foram adicionados $300 \mathrm{~mL}$ uma solução de formaldeído a $4 \%$, para a conservação da fauna, sendo também adicionadas gotas de detergente, para reduzir a tensão superficial da solução, facilitando assim a captura dos organismos. Segundo Aquino et al. (2006), as armadilhas devem permanecer no campo durante o período de sete dias. Contudo, em função da dificuldade de acesso as áreas, as armadilhas permaneceram 10 dias. Após esse período, as armadilhas foram retiradas do solo e encaminhadas para o laboratório, sendo tomados os devidos cuidados com sua limpeza. Posteriormente, adicionou-se álcool $(70 \%)$ em cada amostra, para preservar os organismos. Cabe ressaltar que, mesmo passados mais dias no campo, os organismos possuíam seus caracteres morfológicos intactos, não influindo em sua identificação. Desta forma, a triagem foi realizada com auxílio de lupa binocular, sendo os indivíduos identificados em grandes grupos taxonômicos, ordem, classe ou família, baseado em Gallo et al. (1988) e Dindal (1990).

\section{Atividade de organismos e índices ecológicos de diversidade}

Para avaliar a atividade da fauna do solo, transformou-se o número de indivíduos coletados para número de indivíduos/armadilha/dia (ind arm $^{-1}$ dia $\left.^{-1}\right)$. Também foram calculados índices ecológicos de diversidade, como riqueza total (número total de grupos taxonômicos), riqueza média (número médio de grupos presentes nas amostras) e índice de equidade de Pielou (PIELOU, 1977).

\section{Análise dos dados}

Os fatores de estudo considerados neste trabalho foram os estádios sucessionais (FEI, FEM e FEA) e os meses de coleta (abril e agosto), sendo que para ambos os fatores comparou-se a atividade dos organismos e riqueza dos grupos.

Os resultados obtidos, para ambos os fatores de estudo, foram submetidos à análise de normalidade da distribuição dos erros (teste de Lilliefors) e homogeneidade das variâncias dos erros (teste de Cochran) (RIBEIRO JÚNIOR, 2001). Os dados atenderam às pressuposições da análise de variância, sendo os valores médios comparados por meio do teste $t$ de Bonferroni, a $5 \%$ de probabilidade $(\mathrm{p}<0,05)$ (FERREIRA, 2003).
Foi realizada uma análise multivariada dos componentes principais (ACP) com o objetivo de integrar as informações dos diferentes grupos da fauna nas áreas e meses em que ocorreram. Para tanto, utilizou-se o pacote estatístico Canoco (TER BRAAK e SMILAUER, 2002).

\section{RESULTADOS E DISCUSSÃO}

\section{Composição estrutural da fauna edáfica}

Na primeira amostragem, realizada em abril de 2009, foram contabilizados 2929 indivíduos. Desse total, $16 \%$ encontravam-se na FEI, $27 \%$ na FEM e 57\% na FEA. Em agosto do mesmo ano, dos 7787 indivíduos quantificados, 19\% ocorreram na FEI, 37\% na FEM e 44\% na FEA. Independente da época de amostragem, observou-se o aumento da porcentagem do número total de indivíduos em função do processo sucessional.

Segundo Mueller-Dombois e Ellenberg (1974), durante a sucessão, ocorrem alterações na composição e na riqueza de espécies vegetais, exclusão competitiva e aumento na complexidade estrutural da vegetação. Essas mudanças na vegetação das florestas também são acompanhadas por alterações no habitat, como diminuição da intensidade luminosa, incremento de biomassa e disponibilidade de nutrientes no solo (GUARIGUATA e OSTERTAG, 2001). Nesse contexto, as mudanças ocorridas durante o processo sucessional, em especial as relacionadas à complexidade estrutural da vegetação e incremento de biomassa, podem ter influenciado a dinâmica da fauna edáfica estudada neste trabalho.

Na primeira coleta, os 2929 indivíduos foram classificados em 20 grupos taxonômicos, sendo estes: Acari, Araneae, Auchenorrhyncha, Coleoptera, Diplopoda, Diptera, Entomobryomorpha, Formicidae, Gastropoda, Heteroptera, Hymenoptera, Isopoda, Isoptera, Larva de Coleoptera, Larva de Diptera, Larva de Lepidoptera, Orthoptera, Poduromorpha, Symphypleona e Thysanoptera. Desse total, 18 foram verificados na FEA, 17 na FEM e 15 na FEI. Treze grupos ocorreram nas três áreas. Sete grupos não foram observados em todas as áreas, sendo alguns exclusivos de um estádio sucessional, como Isoptera na FEI, e Gastropoda e Larva de Lepidoptera na FEA.

Em agosto, os 7787 indivíduos coletados foram identificados em 28 grupos taxonômicos, sendo estes: Acari, Araneae, Archaeognatha, 
Auchenorrhyncha, Blattodea, Chilopoda, como Neuroptera na FEI e Chilopoda, Embioptera Coleoptera, Diplopoda, Diptera, Embioptera, e Opilionida na FEA. Na FEM, em ambos os meses Entomobryomorpha, Formicidae, Heteroptera, Hymenoptera, Isopoda, Larva de Coleoptera, Larva de Diptera, Larva de Lepidoptera, Neuroptera, Opilionida, Orthoptera, Poduromorpha, Pseudoscorpionida, Psocoptera, Sternorrhyncha, Symphypleona, Thysanura, Thysanoptera. Do total dos grupos nesse mês, 18 foram observados nas três áreas, sendo que 10 não ocorreram em todas as áreas. Alguns foram encontrados somente em uma área, avaliados, não foi observada presença exclusiva de um determinado grupo.

Em relação à comparação da atividade dos grupos entre as áreas, na Tabela 2 são apresentados os grupos nos quais a atividade diferiu. De maneira geral, maior atividade de grupos foi constatada na FEA.

Em abril, sete grupos expressaram maior atividade na FEA, sendo estes: Acari, Araneae,

TABELA 2: Atividade dos grupos taxonômicos ${ }^{1}$ (indivíduos armadilha ${ }^{-1}$ dia $^{-1}$ ) nos diferentes estádios sucessionais, em abril e agosto de 2009, Pinheiral - RJ.

TABLE 2: Activity of taxonomic groups ${ }^{1}$ (individuals trap $^{-1}$ day $^{-1}$ ), in different successional stages in April and August 2009, Pinheiral, RJ state.

\begin{tabular}{|c|c|c|c|c|c|c|}
\hline \multirow{3}{*}{ Grupos Taxonômicos } & \multicolumn{2}{|c|}{ FEI } & \multicolumn{2}{|c|}{ FEM } & \multicolumn{2}{|c|}{ FEA } \\
\hline & \multicolumn{6}{|c|}{ 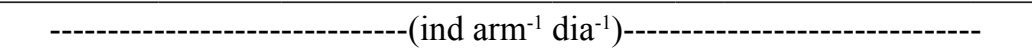 } \\
\hline & \multicolumn{6}{|c|}{ abril de 2009} \\
\hline Acari & 0,04 & B & 0,12 & B & 0,59 & A \\
\hline Araneae & 0,09 & $\mathrm{~B}$ & 0,12 & $\mathrm{~B}$ & 0,42 & A \\
\hline Diptera & 0,12 & $\mathrm{~B}$ & 0,37 & $\mathrm{AB}$ & 0,59 & A \\
\hline Entomobryomorpha & 1,14 & $\mathrm{~B}$ & 2,03 & $\mathrm{~B}$ & 8,19 & A \\
\hline Formicidae & 0,09 & $\mathrm{~B}$ & 0,43 & $\mathrm{~B}$ & 1,43 & A \\
\hline Heteroptera & 0,36 & $\mathrm{~A}$ & 0,13 & $\mathrm{~A}$ & 0,00 & $\mathrm{~B}$ \\
\hline Hymenoptera & 0,07 & $\mathrm{~B}$ & 0,06 & $\mathrm{~B}$ & 0,32 & $\mathrm{~A}$ \\
\hline Isopoda & 0,01 & $\mathrm{~B}$ & 0,01 & $\mathrm{~B}$ & 0,51 & $\mathrm{~A}$ \\
\hline Larva de Diptera & 0,31 & A & 0,07 & $\mathrm{~B}$ & 0,12 & $\mathrm{~A}$ \\
\hline Orthoptera & 0,05 & $\mathrm{~B}$ & 0,32 & A & 0,42 & $\mathrm{~A}$ \\
\hline \multirow[t]{2}{*}{ Symphypleona } & 0,12 & $\mathrm{~B}$ & 1,39 & $\mathrm{~A}$ & 2,24 & $\mathrm{~A}$ \\
\hline & \multicolumn{6}{|c|}{ agosto de 2009} \\
\hline Acari & 0,30 & $\mathrm{~B}$ & 0,56 & $\mathrm{AB}$ & 1,49 & $\mathrm{~A}$ \\
\hline Araneae & 0,24 & $\mathrm{~B}$ & 0,33 & $\mathrm{~B}$ & 1,13 & $\mathrm{~A}$ \\
\hline Coleoptera & 0,21 & $\mathrm{~B}$ & 0,19 & $\mathrm{~B}$ & 1,21 & $\mathrm{~A}$ \\
\hline Diptera & 0,51 & $\mathrm{~B}$ & 0,98 & B & 3,64 & $\mathrm{~A}$ \\
\hline Entomobryomorpha & 11,52 & $\mathrm{~B}$ & 20,08 & A & 13,92 & $\mathrm{AB}$ \\
\hline Formicidae & 0,17 & $\mathrm{~B}$ & 0,25 & $\mathrm{~B}$ & 3,58 & $\mathrm{~A}$ \\
\hline Hymenoptera & 0,07 & $\mathrm{~B}$ & 0,09 & $\mathrm{~B}$ & 0,54 & $\mathrm{~A}$ \\
\hline Isopoda & 0,05 & $\mathrm{~B}$ & 0,10 & $\mathrm{~B}$ & 0,48 & $\mathrm{~A}$ \\
\hline Orthoptera & 0,27 & B & 0,42 & A & 2,85 & $\mathrm{~A}$ \\
\hline Poduromorpha & 0,14 & B & 1,83 & $\mathrm{~B}$ & 3,13 & A \\
\hline Pseudoscorpionida & 0,00 & $\mathrm{~B}$ & 0,03 & A & 0,01 & $\mathrm{AB}$ \\
\hline Psocoptera & 0,01 & B & 0,03 & A & 0,20 & $\mathrm{~A}$ \\
\hline Symphypleona & 0,50 & $\mathrm{~B}$ & 3,51 & $\mathrm{~A}$ & 1,31 & $\mathrm{~B}$ \\
\hline
\end{tabular}

Em que: ${ }^{1}$ Médias de 10 repetições; valores seguidos com letras diferentes na linha diferem entre si $(\mathrm{P}<0,05)$, pelo teste $\mathrm{t}$ de Boferroni; FEI - Floresta em estádio inicial; FEM - Floresta em estádio médio; FEA - Floresta em estádio avançado. 
Diptera, Entomobryomorpha, Formicidae, Hymenoptera e Isopoda. Em agosto mesmo padrão ocorreu no estádio avançado, totalizando oito grupos, sendo estes: Acari, Araneae, Coleoptera, Diptera, Formicidae, Hymenoptera, Isopoda e Poduromorpha (Tabela 2).

A presença de um determinado grupo e/ ou grupos em um sistema pode ser indicativa da qualidade do ambiente (LIMA et al., 2007; MELO et al., 2009; CUNHA et al., 2012). Assim, observouse que, independente do mês de amostragem, alguns grupos só apareceram em um estádio sucessional, como o cupim (Isoptera) e a formigaleão (Neuroptera) na FEI, e os opiliões (Opilionida), lacraia (Chilopoda), Embioptera e Gastropoda na FEA.

Mesmo Isoptera, sendo representado com um indivíduo, sua presença na FEI pode indicar um ambiente que ainda possui herança de atividades agrícolas e de pecuária, que antecederam a formação da capoeira em estádio inicial, em que esses organismos podem ainda estar utilizando como recurso alimentar as raízes das culturas anteriormente cultivadas. Aliado a isso, a atividade pouco expressiva de grupo predadores na FEI pode estar contribuindo com a presença desse grupo. Já a ocorrência de alguns grupos na FEA, em especial, os predadores opiliões e lacraias, além também dos pseudoescorpiões, reflete a complexidade da cadeia trófica desse ambiente, indicando, possivelmente, o equilíbrio desse estádio sucessional.

$\mathrm{Na}$ FEA, em ambas as amostragens, além do maior número de grupos associados, verificouse atividade maior de alguns grupos, como Acari, Araneae, Diptera, Formicidae, Hymenoptera e Isopoda (Tabela 2). Em função disso, é possível observar a influência do estádio sucessional da floresta na estrutura da fauna edáfica, em especial na FEA, em que foi constatado maior número de indivíduos associados, bem como maior atividade de alguns grupos. Além disso, foi possível observar, dentre os grupos presentes nesse estádio, grupos com diferentes funções no ecossistema, como predadores (Araneae, Opilionida, Chilopoda e Pseudoscorpionida), saprófagos (Isopoda) e outros que podem ter essas características e outras funcionalidades, dependendo das espécies presentes (Acari, Diptera e Formicidae). Moço et al. (2005) caracterizando a comunidade edáfica em diferentes coberturas vegetais no RJ, também verificaram a presença do grupo Pseudoscorpionida na floresta preservada. Toledo (2003) encontrou maior atividade de alguns grupos e a presença de predadores nas áreas em que o processo de sucessão encontrava-se avançado. O autor atribuiu a presença de predadores no estádio avançado às características favoráveis proporcionadas por essa floresta, em que houve melhoria na estrutura da cadeia alimentar. Begon et al. (2005) salientam que os sistemas florestais ao evoluírem tendem a um equilíbrio dinâmico, com uma maior complexidade estrutural, redundância funcional e maior controle dos processos ecológicos, e, complementam que, nessa fase, a ocorrência de predadores indica uma estrutura trófica mais controlada, com redistribuição de energia entre grande número de espécies.

Diante do que foi apresentado, é possível inferir que as condições ambientais da floresta em estádio avançado (FEA), reflexo principalmente da complexidade estrutural da vegetação, estão proporcionando um ambiente favorável para o estabelecimento e desenvolvimento da fauna como um todo. Associado a isso, a presença de grupos com diferentes funções na FEA está relacionada com a heterogeneidade da distribuição dos recursos vegetais, causada principalmente pela maior diversidade de espécies. Tews et al. (2004) relatam que uma maior diversidade de espécies é capaz de proporcionar, por meio de um aporte de serapilheira diversificado, uma maior quantidade de nichos potenciais e formas de exploração dos recursos, resultando, portanto, no aumento na diversidade funcional da comunidade. Essa hipótese pode ser confirmada neste estudo, em que foi constatado na área FEA maior deposição anual de serapilheira e melhor qualidade química desse material (Tabela 1).

Com relação à composição estrutural da fauna entre os meses de coleta, na FEI, dos 23 grupos, seis diferiram, sendo que, em agosto, quatro grupos expressaram maior atividade, sendo estes: Acari, Diptera, Entomobryomorpha e Orthoptera. Os grupos Heteroptera e Poduromorpha foram observados em maior número em abril (Tabela 3). Na FEM foram determinados 26 grupos taxonômicos, sendo que seis se destacaram com maior número em agosto, como Acari, Araneae, Auchenorrhyncha, Diptera, Entomobryomorpha e Symphypleona (Tabela 3). Nessa área, em abril, apenas o grupo Coleoptera representou maior atividade. Já na FEA, dos 28 grupos identificados, os grupos Acari, Araneae, Coleoptera, Diptera, Entomobryomorpha, Formicidae, Orthoptera e Poduromorpha apresentaram maior atividade em agosto. 
TABELA 3: Atividade dos grupos taxonômicos ${ }^{1}$ (indivíduos armadilha ${ }^{-1}$ dia $^{-1}$ ) entre abril (abr.) e agosto (ago.) de 2009, para os diferentes estádios sucessionais, Pinheiral - RJ.

TABLE 3: Activity of taxonomic groups ${ }^{1}$ (individuals trap ${ }^{-1}$ day $^{-1}$ ) between April (apr.) and August (aug.) 2009, for the different successional stages, Pinheiral, RJ state.

\begin{tabular}{|c|c|c|c|c|c|c|c|c|c|}
\hline \multirow{2}{*}{$\begin{array}{c}\text { Grupos } \\
\text { Taxonômicos }\end{array}$} & \multicolumn{3}{|c|}{ FEI } & \multicolumn{3}{|c|}{ FEM } & \multicolumn{3}{|c|}{ FEA } \\
\hline & abr. & ago. & & abr. & ago. & & abr. & ago. & \\
\hline Acari & 0,04 & 0,30 & $*$ & 0,12 & 0,56 & $*$ & 0,59 & 1,49 & $*$ \\
\hline Araneae & 0,09 & 0,24 & ns & 0,12 & 0,33 & $*$ & 0,42 & 1,13 & $*$ \\
\hline Archaeognatha & - & - & - & 0,00 & 0,01 & $\mathrm{~ns}$ & 0,00 & 0,01 & ns \\
\hline Auchenorrhyncha & 0,02 & 0,09 & $\mathrm{~ns}$ & 0,08 & 0,27 & $*$ & 0,04 & 0,16 & ns \\
\hline Blattodea & 0,00 & 0,20 & ns & - & - & - & 0,00 & 0,04 & ns \\
\hline Chilopoda & - & - & - & - & - & - & 0,00 & 0,01 & ns \\
\hline Coleoptera & 0,40 & 0,21 & ns & 0,48 & 0,19 & $*$ & 0,66 & 1,21 & $*$ \\
\hline Diplopoda & 0,00 & 0,01 & ns & 0,01 & 0,02 & $\mathrm{~ns}$ & 0,00 & 0,01 & ns \\
\hline Diptera & 0,12 & 0,51 & $*$ & 0,37 & 0,98 & $*$ & 0,59 & 3,64 & $*$ \\
\hline Embioptera & - & - & - & - & - & - & 0,00 & 0,01 & ns \\
\hline Entomobryomorpha & 1,14 & 11,52 & $*$ & 2,03 & 20,08 & $*$ & 8,19 & 13,92 & $*$ \\
\hline Formicidae & 0,09 & 0,17 & ns & 0,43 & 0,25 & ns & 1,43 & 3,58 & $*$ \\
\hline Gastropoda & - & - & - & - & - & - & 0,01 & 0,00 & ns \\
\hline Heteroptera & 0,36 & 0,07 & $*$ & 0,13 & 0,00 & $*$ & 0,00 & 0,11 & $*$ \\
\hline Hymenoptera & 0,07 & 0,07 & $\mathrm{~ns}$ & 0,06 & 0,09 & $\mathrm{~ns}$ & 0,32 & 0,54 & ns \\
\hline Isopoda & 0,01 & 0,05 & ns & 0,01 & 0,10 & $\mathrm{~ns}$ & 0,51 & 0,48 & ns \\
\hline Isoptera & 0,01 & 0,00 & ns & - & - & - & - & - & - \\
\hline Larva de Coleoptera & 0,00 & 0,04 & ns & 0,01 & 0,02 & $\mathrm{~ns}$ & 0,02 & 0,12 & ns \\
\hline Larva de Diptera & 0,31 & 0,22 & ns & 0,07 & 0,19 & ns & 0,12 & 0,15 & ns \\
\hline Larva de Lepidoptera & 0,00 & 0,01 & ns & 0,00 & 0,01 & ns & 0,02 & 0,01 & ns \\
\hline Neuroptera & 0,00 & 0,01 & ns & - & - & - & - & - & - \\
\hline Opilionida & - & - & - & - & - & - & 0,00 & 0,03 & ns \\
\hline Orthoptera & 0,05 & 0,27 & $*$ & 0,32 & 0,42 & $\mathrm{~ns}$ & 0,42 & 2,85 & $*$ \\
\hline Poduromorpha & 1,75 & 0,14 & $*$ & 1,93 & 1,83 & ns & 1,08 & 3,13 & $*$ \\
\hline Pseudoscorpionida & - & - & - & 0,00 & 0,03 & ns & 0,00 & 0,01 & ns \\
\hline Psocoptera & 0,00 & 0,01 & ns & 0,00 & 0,03 & $\mathrm{~ns}$ & 0,00 & 0,20 & $*$ \\
\hline Sternorrhyncha & 0,00 & 0,01 & ns & 0,00 & 0,01 & ns & 0,00 & 0,01 & ns \\
\hline Symphypleona & 0,12 & 0,50 & ns & 1,39 & 3,51 & $*$ & 1,37 & 2,24 & ns \\
\hline Thysanura & - & - & - & 0,00 & 0,02 & ns & 0,00 & 0,02 & ns \\
\hline Thysanoptera & 0,00 & 0,03 & ns & 0,01 & 0,04 & ns & 0,06 & 0,10 & ns \\
\hline
\end{tabular}

Em que: ${ }^{1}$ Médias de 10 repetições; * valores diferem significativamente entre meses pelo teste $\mathrm{F}(\mathrm{p}<0,05)$; ns: não significativo; FEI - Floresta em estádio inicial; FEM - Floresta em estádio médio; FEA - Floresta em estádio avançado.

A partir dos resultados, verificou-se no mês agosto, para ambos os estádios sucessionais, maior atividade de alguns grupos, como Acari, Diptera e Entomobryomorpha. Além disso, somente nesse mês constatou-se presença de outros, como Psocoptera e Sternorrhyncha. Esse fato é corroborado por Fernandes et al. (2011), que verificaram em seus estudos que muitos grupos da fauna edáfica são influenciados até mesmo por pequenas variações ambientais.

Como observado no presente estudo, o padrão de influência da sazonalidade na estrutura da comunidade edáfica, bem como no aumento das populações, tem sido constatado por diversos 
estudos (MOÇO et al., 2005; GOMES et al., 2007; MUSSURY et al., 2008; MENEZES et al., 2009; CALVI et al., 2010; CUNHA-NETO et al., 2012), os quais explicam que as diferenças encontradas entre os meses, épocas ou períodos analisados estão associadas, principalmente, com a precipitação. Essa hipótese pode ser ratificada neste estudo, sendo a maior atividade de alguns grupos e a presença expressiva de outros em agosto, mês caracterizado com maior precipitação, valor médio entre áreas de $19 \mathrm{~mm}$, enquanto abril apresentou $10 \mathrm{~mm}$ (DINIZ, 2011).

Diante do exposto, a fauna do solo, quanto à sua estrutura, possivelmente, foi influenciada pela variação sazonal de recursos, impostos pelos fatores ecológicos, como a precipitação. Esse fator, associado com fatores bióticos do meio, como exemplo serapilheira, pode ter contribuído com a formação de diferentes microssítios (MOÇO et al., 2005), que, por sua vez, alteraram a dinâmica da comunidade como um todo, e também a dinâmica de alguns grupos, seja pelo aumento de sua população, ou por sua presença apenas nessa época (FERNANDES et al., 2011).

A análise dos componentes principais, realizada para integrar as informações dos diferentes grupos da fauna nos estádios sucessionais e meses em que ocorreram, evidenciou que os fatores de estudo, explicaram $33,3 \%$ da variabilidade total dos dados da comunidade da fauna edáfica, sendo que o componente principal 1 (CP1) explicou $24,4 \%$ da variabilidade e o componente principal 2 (CP2) explicou $8,9 \%$. Cabe ainda ressaltar, que, dos fatores analisados, o fator estádio sucessional explicou $18 \%$ da variabilidade dos dados da comunidade, enquanto o fator mês $13,2 \%$.

Ao analisar a Figura 1, constata-se a diferenciação dos estádios sucessionais da floresta quanto à correlação com a estrutura edáfica, a qual indica a separação das áreas em diferentes quadrantes, como, por exemplo, a FEA que ficou no quadrante oposto às outras áreas, e apresentou maior número de grupos associados. Também é possível observar maiores semelhanças entre as áreas de FEI e FEM, as quais se localizaram em mesmo quadrante, e apresentaram menor número de grupos associados. Portanto, é possível deduzir que, quanto à associação de grupos, a FEM se assemelha mais com a FEI, do que com a FEA. Outra informação, que corrobora os resultados já apresentados, se refere à influência da sazonalidade na dinâmica da fauna. Na Figura 1 verifica-se maior associação de

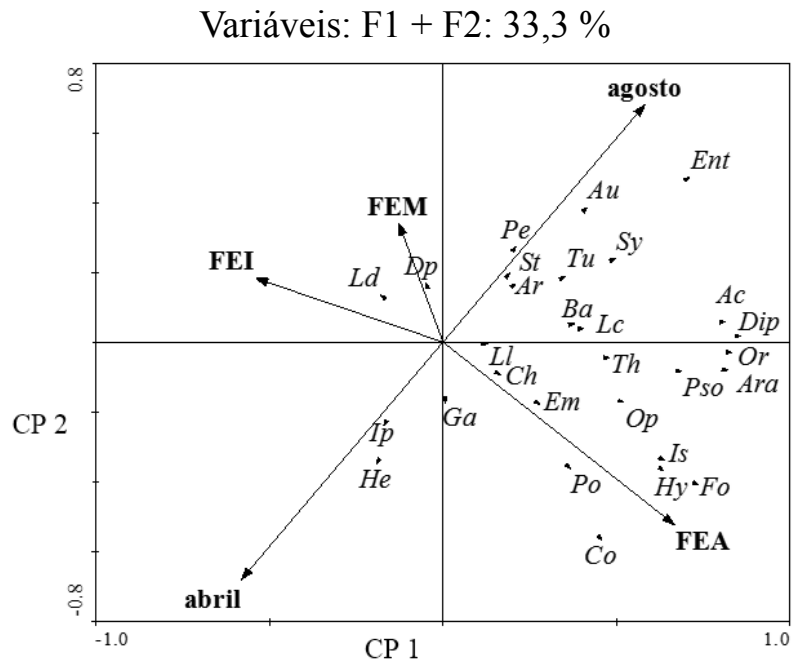

Em que: Ac = Acari; Ara = Araneae; Ar $=$ Archaeognatha; $\mathrm{Au}=$ Auchenorrhyncha; $\mathrm{Ba}=$ Blattodea; $\mathrm{Ch}=$ Chilopoda; Co = Coleoptera; $\mathrm{Dp}$ = Diplopoda; Dip = Diptera; Em = Embioptera; Ent = Entomobryomorpha; Fo = Formicidae: $\mathrm{Ga}=$ Gastropoda; He = Heteroptera; Hy = Hymenoptera; Is = Isopoda; Ip = Isoptera; Lc = Larva de Coleoptera; Ld = Larva de Diptera; Ll = Larva de Lepidoptera; $\mathrm{Ne}=$ Neuroptera; Op = Opilionida $;$ Or = Orthoptera; Po = Poduromorpha; Pe = Pseudoscorpionida; Pso = Psocoptera; St = Sternorrhyncha; Sy = Symphypleona; $\mathrm{Th}=$ Thysanoptera; $\mathrm{Tu}=$ Thysanura.

FIGURA 1: Diagrama de ordenação resultante da análise de componentes principais (ACP) da atividade total dos grupos da fauna edáfica, em abril e agosto de 2009, nas áreas de Floresta em estádio inicial (FEI), Floresta em estádio médio (FEM) e Floresta em estádio avançado (FEA), Pinheiral - RJ.

FIGURE 1: Ordination diagram resulting from principal component analysis (PCA) of the total activity of groups of soil fauna in April and August 2009, in the areas of forest in initial stage (FIS), Forest in intermediate stage (FINS) and forest in advanced stage (FAS), Pinheiral, RJ state.

grupos no mês de agosto, o qual se caracterizou com maior precipitação.

Por meio da análise dos componentes principais é possível confirmar a resposta da estrutura da fauna edáfica, quanto à atividade de grupos, aos fatores áreas e mês, ficando evidente a associação de maior número de grupos com a FEA 
e o mês de agosto.

\section{Índices ecológicos e composição relativa da fauna edáfica}

Além do estudo da estrutura da fauna, no qual um determinado grupo ou grupos são utilizados como indicadores das modificações do ambiente, pode-se também inferir sobre essas alterações por análises de índices ecológicos. Essa abordagem permite avaliar a comunidade da fauna do solo em um sentido amplo, por meio, por exemplo, da atividade total e estimadores de diversidade (Tabela 4).

Em abril, verificou-se na FEA atividade total de 16,73 ind arm $^{-1} \mathrm{dia}^{-1}$, sendo essa superior

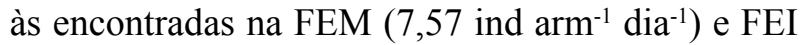
(4,58 ind $\left.\mathrm{arm}^{-1} \mathrm{dia}^{-1}\right)$ (Tabela 4). Na FEI, em agosto, também se observaram menores valores. Contudo, as áreas de FEM e FEA nesse mês não se diferiram, embora exista uma tendência de maior valor na FEA (Tabela 4).

Com relação às variáveis de diversidade, a riqueza média em abril expressou valor inferior na FEI com 7,40, quando comparada com a FEM $(10,10)$ e FEA $(12,00)$, as quais não diferiram (Tabela 4). Em agosto, a riqueza média foi maior na FEA $(15,80)$, quando comparada com a $\operatorname{FEM}(12,7)$ e a FEI $(10,8)$, que não se diferiram (Tabela 4$)$.

Os valores de atividade total e riqueza média, em ambos os meses, evidenciaram que, de maneira geral, a comunidade da fauna do solo respondeu às alterações no ambiente, em função do avanço sucessional da vegetação (Tabela 4). Esse padrão de aumento do número de indivíduos e riqueza média em função do avanço sucessional ou preservação do ambiente foi também constatado por Menezes et al. (2009), avaliando a comunidade da macrofauna edáfica em diferentes estádios sucessionais de Mata Atlântica, Pinheiral - RJ, e por Moço et al. (2005), caracterizando a fauna edáfica em florestas preservadas, florestas não preservadas e capoeira no Norte Fluminense. Gomes et al. (2007) avaliando o impacto de fragmentação sobre a mesofauna, em Dourados - MS, e Mussury et al. (2008), estudando a flutuação populacional da fauna edáfica nas mesmas áreas, também verificaram o padrão de aumento do número de indivíduos e riqueza, em função do grau de preservação do ambiente. Ambos os autores, relataram que os resultados do maior número de indivíduos e riqueza média da fauna, constatados em seus estudos, estão associados ao maior número de espécies vegetais verificadas nas áreas avançadas ou preservadas. Ainda complementam que, possivelmente, a complexidade estrutural da vegetação, em termos de diversidade, está proporcionando condições favoráveis para o desenvolvimento da comunidade da fauna.

Diante disso, é possível inferir que a maior diversidade de espécies vegetais na FEA influiu em maior deposição e melhor qualidade

TABELA 4: Atividade total ${ }^{1}$ (indivíduos armadilha ${ }^{-1}$ dia $^{-1}$ )e índices ecológicos da fauna edáfica, nos meses de abril e agosto de 2009, para os diferentes estádios sucessionais, Pinheiral - RJ.

TABLE 4: Total activity ${ }^{1}$ (individuals trap $^{-1}$ day $^{-1}$ ) and ecological index of soil fauna, in the months of April and August 2009, for the different successional stages, Pinheiral, RJ state.

\begin{tabular}{|c|c|c|c|c|}
\hline \multirow{2}{*}{ Áreas de estudo } & Total de ind $\operatorname{arm}^{-1} \operatorname{dia}^{-1} \pm$ Erro Padrão & Riqueza Total & Riqueza Média & Pielou (U) \\
\hline & \multicolumn{4}{|c|}{ abril de 2009} \\
\hline FEI & $4,58 \pm 1,22$ b B & 15 & $7,40 \mathrm{~b} \mathrm{~B}$ & 0,69 \\
\hline FEM & $7,57 \pm 1,03 \mathrm{~b}$ B & 17 & 10,10 a B & 0,71 \\
\hline \multirow[t]{2}{*}{ FEA } & $16,73 \pm 3,14$ a B & 18 & 12,00 a B & 0,63 \\
\hline & \multicolumn{4}{|c|}{ agosto de 2009} \\
\hline FEI & $14,50 \pm 2,89 \mathrm{~b} \mathrm{~A}$ & 22 & $10,80 \mathrm{~b} \mathrm{~A}$ & 0,33 \\
\hline FEM & $28,99 \pm 2,80$ a A & 22 & $12,70 \mathrm{~b} \mathrm{~A}$ & 0,40 \\
\hline FEA & $34,33 \pm 4,68$ a A & 26 & 15,80 a A & 0,63 \\
\hline
\end{tabular}

Em que: *Médias de 10 repetições; valores seguidos com letras diferentes, minúsculas na comparação entre áreas e maiúsculas na comparação entre meses, diferem entre si $(\mathrm{P}<0,05)$, pelo teste $\mathrm{t}$ de Bonferroni; FEI - Floresta em estádio inicial; FEM - Floresta em estádio médio; FEA - Floresta em estádio avançado. 
química da serapilheira (MACHADO, 2011), melhorando a estrutura do habitat e aumentando o recurso alimentar disponível (MOÇO et al., 2005; MENEZES et al., 2009), favorecendo, assim, a colonização e desenvolvimento da fauna nessa área.

Com relação às diferenças encontradas entre os meses de coleta, como o verificado para estrutura da fauna, também se observaram maiores valores de atividade e riqueza média da comunidade no mês de agosto, em todas as áreas (Tabela 3). Essa influência da sazonalidade na comunidade edáfica, como relatado anteriormente, tem sido estudada por diversos autores (MOÇO et al., 2005; GOMES et al., 2007; MUSSURY et al., 2008; MENEZES et al., 2009; CALVI et al., 2010; CUNHA-NETO et al., 2012). O padrão de maior número de organismos no verão não foi constatado nesse estudo, sendo os maiores valores encontrados em agosto, mês que compreende o período seco. No entanto, a variação da atividade de organismos, bem como a de riqueza, é decorrente dos valores de precipitação.

Desta forma, observa-se a sensibilidade da comunidade edáfica às mudanças climáticas, em que os maiores valores de precipitação em agosto, possivelmente, influenciaram o crescimento vegetal, e, consequentemente, a oferta de alimento. Essas condições criam um ambiente mais propício para a colonização da fauna (MOÇO et al., 2005), seja pelo acúmulo de serapilheira ou água, ou ambos, reduzindo assim as variações da temperatura do ambiente serapilheira-solo que, por sua vez, favoreceu o aumento da colonização dos diversos grupos.

Por outro lado, os sítios formados não necessariamente favorecem todos os grupos da fauna, sendo que poucos podem se beneficiar das condições impostas pelos fatores ecológicos que ocorrem no habitat, aumentando assim sua atividade. Neste sentido, um índice que comumente tem sido utilizado para averiguar os padrões de dominância é o índice de Pielou, que representa a uniformidade da distribuição do número de indivíduos nos diferentes grupos. Os menores valores obtidos, por esse índice, numa escala de 0 a 1 , representam comunidades menos uniformes, em que a dominância de um ou mais grupos é mais acentuada (PIELOU, 1977).

Constatou-se que o índice de equidade apresentou variações entre os estádios sucessionais e meses analisados (Tabela 4). Destacaram-se as variações entre áreas no mês de agosto, e entre os meses nas áreas de FEI e FEM. Em abril não foram constatadas grandes variações dos valores do índice, sendo os valores de 0,71, 0,69 e 0,63, respectivamente, para as áreas de FEM, FEI e FEA (Tabela 4). Entretanto, em agosto foram observadas maiores variações, em que se observa uma tendência de menores valores na FEI $(0,33)$ e FEM $(0,40)$, e maior valor na $\mathrm{FEA}(0,63)$.

A variabilidade dos valores de equidade pode ser decorrente dos valores de riqueza e dominância de grupos, ou seja, o índice será maior quando a riqueza for alta e a dominância de poucos grupos for baixa. Esse padrão foi confirmado nos meses analisados. Em abril, mesmo não sendo constatadas grandes variações entre as áreas, o valor da equidade na $\operatorname{FEA}(0,63)$ se deve à alta dominância do grupo Entomobryomorpha, o qual representou $48 \%$ do total da atividade média de todos os grupos identificados (Figura 2). Na FEI, o valor de 0,69 se deve a dominância do grupo Poduromorpha, que expressou 38\%. Na FEM não houve um grupo com elevada expressão, mas os grupos Entomobryomorpha e Poduromorpha apareceram com, respectivamente, 27 e 25\% (Figura 2).

Diferindo das poucas variações observadas entre as áreas em abril e corroborando a hipótese de que o índice será maior quando a riqueza for alta e a dominância baixa, maiores variações ocorreram em agosto (Figura 3). Na FEA, o maior valor do índice $(0,63)$ se deve à maior riqueza de grupos, associada à menor dominância do grupo Entomobryomorpha, o qual contribui com $40 \%$ dos efetivos totais. Nas áreas de FEI $(0,33)$ e FEM $(0,40)$, os valores de equidade são baixos, quando comparados com o da FEA $(0,63)$, sendo esse fato devido aos menores valores de riqueza média e a maior dominância do grupo Entomobryomorpha, que representou, praticamente, mais de $70 \%$ da atividade total nas duas áreas (Figura 3).

Quanto às variações do índice de Pielou entre os meses, destacaram-se as ocorridas nos estádios inicial (FEI) e médio (FEM), cujos valores diminuíram do mês de abril para o mês de agosto (Tabela 4). Essas variações ocorreram, principalmente, devido à dominância de poucos grupos (Figuras 2 e 3). Em abril, os valores do índice para as áreas de FEI e FEM foram, respectivamente, de 0,63 e 0,71 , e os grupos que representaram a maior dominância nessas áreas foram os Poduromorpha na FEI com 38\% e os Entomobryomorpha na FEM com 26\% (Figura 2). Em agosto, os valores do índice nas áreas de FEM $(0,40)$ e FEI $(0,33)$ diminuíram, pois a dominância do grupo Entomobryomorpha dobrou, sendo os valores de $69 \%$ na FEM e 


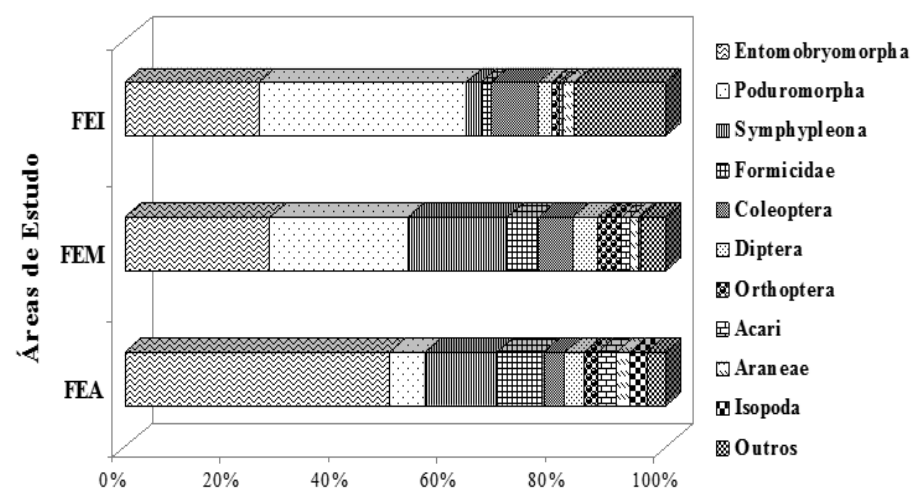

FIGURA 2: Distribuição relativa (\%) dos 10 grupos da fauna edáfica com maior atividade (ind arm $^{-1}$ dia $^{-1}$ ) em abril de 2009, nas áreas de Floresta em estádio inicial (FEI), Floresta em estádio médio (FEM) e Floresta em estádio avançado (FEA), Pinheiral - RJ.

FIGURE 2: Relative distribution (\%) of the 10 groups of soil fauna with more activity $\left(\mathrm{arm} \mathrm{ind}^{-1}\right.$ day $\left.^{-1}\right)$ in April 2009, in the areas of forest in initial stage (FIS), Forest in intermediate stage (FINS) and forest in advanced stage (FAS ), Pinheiral, RJ state.

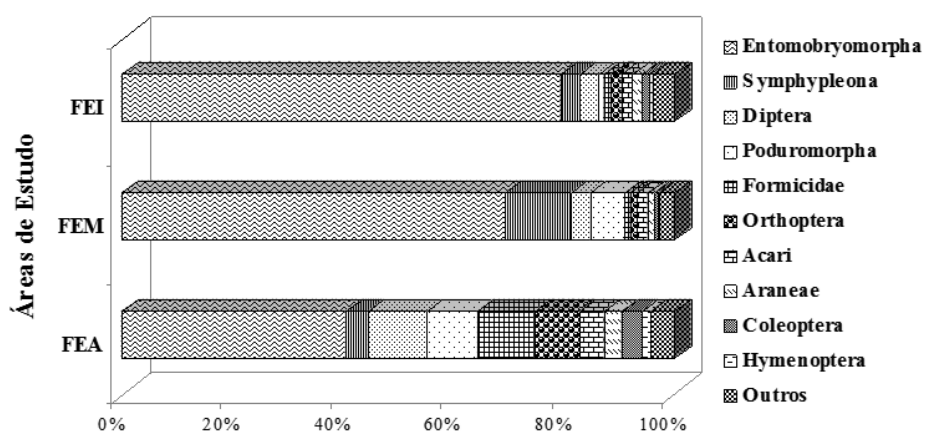

FIGURA 3: Distribuição relativa (\%) dos 10 grupos da fauna edáfica com maior atividade (ind arm-1 dia $^{-1}$ ) em agosto de 2009, nas áreas de Floresta em estádio inicial (FEI), Floresta em estádio médio (FEM) e Floresta em estádio avançado (FEA), Pinheiral - RJ.

FIGURE 3: Relative distribution (\%) of the 10 groups of soil fauna with more activity ( $\mathrm{arm} \mathrm{ind}^{-1}$ day $^{-1}$ ) in August 2009, in the areas of forest in initial stage (FIS), Forest in intermediate stage (FINS) and forest in advanced stage (FAS ), Pinheiral, RJ state.

$79 \%$ na FEI (Figura 3).

$\mathrm{O}$ grupo que mais influenciou os valores do índice de equidade de Pielou, seja nas comparações entre áreas para cada mês seja na comparação entre meses para cada área, foi o grupo Entomobryomorpha, que, de maneira geral, apresentou maior dominância (Figuras 2 e 3). Cunha-Neto et al. (2012), ao estudarem a fauna do solo como indicadora da qualidade do solo em plantios florestais, pastagem e floresta secundária, também verificaram grande influência do grupo Entomobryomorpha nos valores do índice, para ambas as áreas avaliadas. No entanto, os trabalhos de Moço et al. (2005) e Calvi et al. (2010), ambos desenvolvidos em Mata Atlântica, não constataram grande influência do grupo Entomobryomorpha nos valores da equidade. Moço et al. (2005) verificaram que a maior influência no índice de Pielou, verificado na serapilheira da capoeira $(0,43)$, foi devido à alta dominância do grupo Hymenoptera (formigas), o qual correspondeu a $67 \%$ do total de indivíduos capturados. Nesse mesmo compartimento, o percentual do grupo Hymenoptera nas florestas não preservadas (FNP) e preservadas (FP) foi, respectivamente, de $46 \%$ e $48 \%$, e os índices para essas mesmas florestas foram de 0,68 na FNP e 0,65 na FP. Já Calvi et al. (2010), avaliando duas florestas secundárias no Espírito Santo (floresta secundária avançada e floresta secundária), em duas épocas do ano (verão e inverno), verificaram que os grupos 
que mais influenciaram nos valores da equidade foram os Diptera e Formicidae. Segundo os autores, os dípteros (Diptera) tiveram abundância acima de $48 \%$ na FSA, no verão e inverno, e na FS no inverno. Já as formigas influenciaram nos menores valores do índice na FS no verão, com dominância de $68 \%$.

Neste estudo, além dos colêmbolos (Collembola), como exemplo Entomobryomorpha, Poduromorpha e Symphypleona, outros grupos tiveram participação expressiva entre áreas e meses de coleta, e estiveram entre os três grupos mais abundantes, dentre esses Formicidae, Diptera e Coleoptera (Figuras 2 e 3 ).

Em abril, os três grupos mais abundantes na FEI foram Poduromorpha (38\%) e Entomobryomorpha (25\%), e desconsiderando o grupo "outros", cuja alta participação se deve ao elevado número de grupos que apresentaram baixos valores de abundância, o grupo Coleoptera (9\%) representou a terceira maior participação (Figura 2). Na área de FEM, as maiores participações do total de indivíduos foram as dos grupos Entomobryomorpha (27\%), Poduromorpha (25\%) e Symphypleona (18\%). Na FEA, a sequência para a ordem decrescente dos maiores percentuais foi Entomobryomorpha 49\%, Symphypleona $13 \%$ e Formicidae $9 \%$. Os três grupos com maior participação, em ambas as áreas, representaram valores acima de $70 \%$ do total de indivíduos coletados (Figura 2).

Em agosto, os três grupos mais abundantes na FEI foram Entomobryomorpha (79\%), Symphypleona $(3,45 \%)$ e Diptera $(3,52 \%)$, que somados representaram mais de $85 \%$ do total de indivíduos coletados (Figura 3). Na área de FEM destacaram-se os Entomobryomorpha (69\%), Symphypleona (12\%) e Poduromorpha (6\%), que juntos corresponderam a $87 \%$ do total. A sequência para a área de FEA apresenta os grupos Entomobryomorpha (41\%), Diptera $(10,6 \%)$ e Formicidae $(10,43 \%)$, que somados representaram $63 \%$ do total de indivíduos (Figura 3).

Os percentuais dos três grupos mais representativos aumentaram de abril para agosto nas áreas de FEI e FEM, ao passo que na área de FEA houve uma ligeira tendência de diminuição (Figuras 2 e 3). $\mathrm{O}$ aumento na composição relativa dos três grupos na FEI e FEM está relacionado diretamente ao maior número de indivíduos do grupo Entomobryomorpha presentes nessas áreas que, possivelmente, foi decorrente das melhores condições do habitat, causada pela maior precipitação. Associado a isso, nessas áreas, de maneira geral, não houve participação expressiva de grupos predadores, os quais poderiam influenciar na dinâmica da população do grupo Entomobryomorpha, e, consequentemente, em sua expressividade. Já a diminuição na composição relativa desse grupo na FEA pode estar relacionada à melhor estruturação da cadeia trófica, em que, dentre os grupos funcionais constatados, verificouse a maior presença de predadores.

Os colêmbolos também foram dominantes no estudo de Moraes (2005), que avaliou indicadores da restauração de áreas degradadas na Reserva Biológica de Poço das Antas - RJ, dentre esses, a fauna do solo. O autor verificou elevada abundância desse grupo em todos os tratamentos avaliados, sendo a menor participação de $53 \%$ apenas para uma área, nas demais os colêmbolos representaram sempre mais que $75 \%$ do total de indivíduos. Kataguari (2006) também observou alta composição dos colêmbolos, estudando o restabelecimento da fauna edáfica e a qualidade da serapilheira numa floresta estacional semidecídua. A autora verificou que os colêmbolos foram o terceiro grupo com a maior abundância, sendo sua composição relativa inferior somente quando comparada com os ácaros (Oribatidae e não Oribatidae). Souza et al. (2008) notaram o mesmo padrão, observando que o grupo Collembola foi o terceiro de maior participação no total de indivíduos, sendo menos abundante somente que Formicidae e Coleoptera.

Segundo Costa (2002), os colêmbolos são micrófagos, desenvolvendo a atividade predatória de microrganismos, como fungos (TORDOFF et al., 2008; SIDDIKI et al., 2012). Desta forma, a grande expressividade desse grupo na FEI e FEM, principalmente, em agosto, pode ser atribuída à maior abundância de esporos de fungos micorrízicos arbusculares, conforme relatado por Silva et al. (2010). Os autores estudaram esses fungos nas mesmas áreas do presente estudo, e encontraram abundância do número de esporos na ordem de 500 para a área de FEA, 984 na área de FEM e 963 na área de FEI.

A participação expressiva dos dípteros (Diptera) na FEA pode estar relacionada diretamente com a maior deposição de serapilheira nessa área (MACHADO, 2011), a qual está contribuindo para o forrageamento dos indivíduos, e para seu uso como abrigo (CALVI et al. 2010).

Além dos colêmbolos, outro grupo que 
se destacou, principalmente na FEA, foi o das formigas (Formicidae), que nas duas avaliações apresentou-se como o terceiro grupo mais abundante. A presença desse grupo no estádio avançado foi visível no decorrer dos trabalhos de campo, seja pelo seu forrageamento, como também pelos grandes ninhos em alguns trechos da área. Contudo, não foi verificada influência direta nos pontos amostrais, principalmente naqueles que se encontravam próximos aos ninhos. Formicidae foi também um grupo importante no trabalho de Souza et al. (2008) avaliando a estrutura da comunidade da fauna edáfica em fragmentos de Mata Atlântica na Restinga da Marambaia - RJ. Foi o grupo que representou o maior número de indivíduos, conforme observado por Toledo (2003) e Menezes et al. (2009) em floresta secundária com diferentes estádios de sucessão em Pinheiral - RJ. As formigas são animais dominantes na maioria dos ecossistemas terrestres. Nas florestas tropicais, por exemplo, é um dos grupos com maior número de espécies e biomassa (MELO et al., 2009). Por essas características, a riqueza e diversidade desses insetos, além do número de indivíduos, são maiores em ambientes de maior complexidade de nichos presentes (PEREIRA et al., 2007). Este fato foi observado por Pereira et al. (2007) avaliando a fauna de formigas como ferramenta para monitoramento de áreas de mineração reabilitada na Ilha da Madeira - RJ. Os autores verificaram uma fauna diferenciada de formigas e maior riqueza de espécies em parcelas com maior número de espécies arbóreas.

Desta forma, a ocorrência de Formicidae em maiores proporções na FEA, quando comparada às outras áreas (FEM e FEI), pode ser um indicativo de equilíbrio desse estádio sucessional. Ademais, a relevância desse grupo para a comunidade da fauna é atribuída ao hábito social e a repartição do trabalho, atuando em conjunto na redistribuição de partículas da matéria orgânica, melhorando assim a infiltração de água no solo pelo aumento da porosidade e aeração. Assim, esses insetos são considerados de fundamental importância para 0 processo de ciclagem de nutrientes em ecossistemas florestais (ASSAD, 1997).

Em função do exposto, a comunidade da fauna edáfica se mostrou como um indicador da sucessão florestal natural de florestas secundárias, ao evidenciar, por meio de sua atividade, composição estrutural e diversidade, maiores valores em função da trajetória sucessional das florestas.

\section{CONCLUSÕES}

A atividade e a riqueza da fauna aumentaram do mês de abril para o mês de agosto em todos os estádios sucessionais, em função da maior precipitação em agosto.

A estrutura da comunidade edáfica foi influenciada pelos estádios sucessionais da floresta, evidenciando maior atividade de grupos, como Acari, Araneae, Diptera, Formicidae, Hymenoptera e Isopoda, conforme o avanço sucessional.

Dos índices ecológicos, a atividade total e a riqueza média confirmaram a influência do estádio sucessional da floresta na comunidade da fauna edáfica.

Os maiores valores de atividade de grupos, atividade total, riqueza média, além da maior presença de grupos predadores, foram constatados na FEA.

O grupo Entomobryomorpha foi o principal responsável pelas variações do índice de Pielou.

\section{AGRADECIMENTOS}

À Universidade Federal Rural do Rio de Janeiro (UFRRJ), ao programa de Pós-Graduação em Ciências Ambientais e Florestais (PPGCAF), ao Instituto Federal do Rio de Janeiro "Campus Pinheiral", à FAPERJ e à CAPES.

\section{REFERÊNCIAS BIBLIOGRÁFICAS}

ASSAD, M. L. L. Fauna do solo. In: VARGAS, M. A. T.; HUNGRIA, M. Biologia dos solos dos Cerrados. Planaltina, EMBRAPA - CPAC, 1997. p. 363-443.

AQUINO, A. M.; AGUIAR-MENEZES, E. L.; QUEIROZ, J. M. Recomendações para coleta de artrópodes terrestres por armadilhas de queda ("pitfall-traps"). Seropédica: Embrapa Agrobiologia, 2006. 8 p. (Embrapa Agrobiologia, Circular Técnica, 18).

BARLOW, A.J. et al. Litter fall and decomposition in primary, secondary and plantation forests in the Brazilian Amazon. Forest Ecology and Management, v. 247, p. 91-97, 2007.

BALL, B.A. et al. Linkages between below and aboveground communities: decomposer responses to simulated tree species loss are largely additive. Soil Biology \& Biochemistry, v. 41, p. 1155-1163, 2009.

BEGON, M.; TOWNSEND, C. R.; HARPER, J. L. 
Ecology from individuals to ecosystems. Malden, Blackwell Publishing, 2005. 738 p.

CALVI, G. P. et al. Composição da fauna edáfica em duas áreas de floresta em Santa Maria de Jetibá, ES, Brasil. Acta Agronômica , v. 59, p. 37-45. 2010. CORREIA, M. E. F; ANDRADE, A. G. Formação de serapilheira e ciclagem de nutrientes. In: SANTOS, G.A.; CAMARGO, F.A.de. Fundamentos da matéria orgânica do solo: ecossistemas tropicais e subtropicais. 2. ed. Rev. e atual. Porto Alegre: Metrópole. p.137-158, 2008.

COSTA, P. Fauna do Solo em Plantios Experimentais de Eucalyptus grandis Maiden, Pseudosamanea guachapele Dugand e Acacia mangium Willd. 2002.93 p. Dissertação (Mestrado) - Universidade Federal Rural do Rio Janeiro, Seropédica, 2002.

CUNHA NETO, F. V. et al. Soil fauna as an indicator of soil quality in forest stands, pasture and secondary forest. Revista Brasileira de Ciência do Solo, v. 36, p. 1407-1417, 2012.

DAVIS, C. A.; UTRUP, J. S. Response of terretrial invertebrates to high-and-low-diversity grassland restorations in south-central Nebraska. Restoration Ecology, v.18, n.S2, p.479-488, 2010.

DINDAL, D. Soil biology guide. New York: John Wiley and Sons. 1990. 1348 p.

DINIZ, A. R. Dinâmica de fragmentos florestais da Mata Atlântica, na região do Médio Vale do Paraíba do Sul, Rio de Janeiro. 2011. 77 f. Dissertação (Mestrado) - Universidade Federal Rural do Rio de Janeiro, Seropédica, 2011.

FERNANDES., M. M. et al. Aporte e decomposição de serapilheira em áreas de floresta secundária, plantio de sabiá (Mimosa caesalpiniaefolia Benth) e andiroba (Carapa guianenses Aubl.) na FLONA Mário Xavier, RJ. Ciência Florestal, v. 16, p. 163175, 2006.

FERREIRA, D. F. Sistema de Análises Estatísticas. SISVAR 4.6. Lavras: UFLA, n.p. 2003.

GALLO, D. et al. Manual de Entomologia Agrícola. 2. ed. São Paulo: Agronômica Ceres, 1988.

GIEBELMAN, U. C. et al. Diversity and ecosystem functioning: litter decomposition dynamics in the Atlantic Rainforest. Applied Soil Ecology, v. 46, p. 283-290, 2010.

GOMES, A. A. et al. Avaliação do impacto da fragmentação de florestas nativas sobre a mesofauna edáfica na região de Dourados, MS. Revista Ciência e Agrotecnologia, Lavras, v. 31, n. 3, p. 612-618, 2007.
GUARIGUATA, M. R.; OSTERTAG, R. Neotropical secondary succession: changes in structural and functional characteristics. Forest Ecology and Management, v. 148, p. 85-206, 2001.

IBGE - Instituto Brasileiro de Geografia e Estatística. Manual técnico da vegetação brasileira. IBGE, Rio de Janeiro. 1992. 92 p.

KATAGUARI, V.S. Restabelecimento da fauna edáfica e a qualidade da serapilheira na Floresta da USP : área de reflorestamento de Floresta Estacional Semidecidual. Ribeirão Preto. 2006. 53 f. Dissertação (Mestrado) - Faculdade de Filosofia, Ciências e Letras de Ribeirão Preto - Universidade de São Paulo, 2006.

LAVELLE, P. et al. A hierarchical model for decomposition in terrestrial ecosystems: application to soils of the humid tropics. Biotropica, v. 25, n. 2 , p. 130-150, 1993.

LAOSSI, K. R. et al. Effects of plant diversity on plant biomass production and soil macrofauna in Amazonian pastures. Pedobiologia, v. 51, 397-407, 2008.

LIMA, H. V. et al. Indicadores de qualidade do solo em sistemas de cultivo orgânico e convencional no semi-árido Cearense. Revista Brasileira de Ciência do Solo, v. 31, p. 1085-1098, 2007.

MACHADO, D. L. Atributos indicadores da dinâmica sucessional em framento de Mata Atlântica na região do médio vale do Paraíba do Sul, Pinheiral, Rio de Janeiro. 2011. $103 \mathrm{f}$. Dissertação (Mestrado) - Universidade Federal Rural do Rio de Janeiro, Seropédica, 2011.

MELO, F. V. et al. A importância da meso e macrofauna do solo na fertilidade e como bioindicadores. Biologia do Solo. Boletim informativo da SBCS. jan.-abr. 2009.

MAJER, J. D.; BRENNAN, K. E. C.; MOIR, M. $\mathrm{L}$. Invertebrates and the restoration of a forest ecosystem: 30 years of research following bauxite mining in western Australia. Restoration Ecology, v. 15, n. 4; p. 104-115, 2007.

MENEZES, C. E. G. et al. Macrofauna edáfica em estádios sucessionais de floresta estacional semidecídua e pastagem mista em Pinheiral, RJ. Revista Brasileira de Ciência do Solo, v. 33, p. 1647-1656, 2009.

MENEZES, C. E. G. et al. Aporte e decomposição da serapilheira e produção de biomassa radicular em florestas com diferentes estágios sucessionais em Pinheiral, RJ. Revista Ciência Florestal, Santa Maria, v. 20, n. 3, p. 439-452, 2010.

MOÇO, M. K. et al. Caracterização da fauna edáfica 
em diferentes coberturas vegetais na região Norte Fluminense. Revista Brasileira de Ciência do Solo, v. 29, p. 555-564, 2005.

MORAES, L. F. D. Indicadores da restauração de áreas degradadas na Reserva Biológica de Poço das Antas, RJ. 2005. 111 f. Tese (Doutorado) - Universidade Federal Rural do Rio de Janeiro. Instituto de Agronomia. Seropédica, RJ. 2005.

MOREIRA, F. M. S.; HUISING, J.; BIGNELL, D. E. Manual de Biologia dos Solos Tropicais. Amostragem e Caracterização da Biodiversidade. 1. ed. Lavras: UFLA, 2010. 368 p. v. 1.

MUELLER-DOMBOIS, D.; ELLEMBERG, H. Aims and methods of vegetation ecology. New York: Wiley, 1974. 547 p.

MUSSURY, R.M. et al. Flutuação populacional da mesofauna em fragmentos de mata na região de Dourados, MS. Ciência e Agrotecnologia, Lavras, v. 32, n. 2, p. 645-650, 2008.

OLIVEIRA, J. A. Caracterização física da Bacia do Ribeirão Cachimbal-Pinheiral (RJ) e de suas principais paisagens degradadas, Seropédica. 1998. Dissertação (Mestrado) - Universidade Federal Rural do Rio de Janeiro, Seropédica, RJ, 1998.

PEREIRA, M. P. S. et al. Fauna de formigas como ferramenta para monitoramento de área de mineração reabilitada na Ilha da Madeira, Itaguaí, RJ. Revista Ciência Florestal, v. 17, n. 3, p. 197-204, 2007.

PIELOU, E. C. Mathematical ecology. Nem York, Wiley, 1977. $385 \mathrm{p}$.

RIBEIRO JÚNIOR, J.I. Análises estatísticas no SAEG. Viçosa: Universidade Federal de Viçosa, 2001.301p.

SIDDIKY, M. D. et al. Soil biota effects on soil structure: Interactions between arbuscular mycorrizal fungal mycelium and collembolan. (Repost). Soil Biology \& Biochemistry, v. 50, p. 33-39, 2012.

SILVA, C. F. et al. Fungos micorrízicos arbusculares e proteína do solo relacionada à glomalina em áreas de agricultura, pastagem e fragmentos florestais da Mata Atlântica. In: FERTBIO 2010 - Fontes de nutrientes e produção agrícola: modelando o futuro, Guarapari, ES. Anais... (CD-ROM), 2010.

SNYDER, B. A.; HENDRIX, P. F. Current and potential roles of soil macroinvertebrates (earthworms, millipedes and isopods) in ecological restoration. Restoration Ecology., v. 16, p. 629-636, 2008.

SOUZA, R. C. et al. Estrutura da Comunidade da Fauna Edáfica em Fragmentos Florestais na Restinga da Marambaia, RJ. Rev. Bras. Ciências Agrárias, v. 3, n. 1, p. 49-57. 2008.

TER BRAAK, C. J. F.; SMILAUER P. CANOCO Reference manual and CanoDraw for Windows user's guide: Software for Canonical Community Ordination (version 4.5). Micrófagoscomputer Power, Ithaca, 2002.

TOLEDO, L. de O. Aporte de serapilheira, fauna edáfica e taxa de decomposição em áreas de floresta secundária no município de Pinheiral, RJ. 2003. 80 f. Dissertação (Mestrado) - Universidade Federal Rural do Rio de Janeiro, Seropédica, RJ. 2003.

TORDOFF, G. M.; BODDY, L.; JONES, T. H. Species-specific impacts of collembola grazing on fungal foraging ecology. Soil Biology \& Biochemistry., v. 40, p. 434-442, 2008.

TEWS, J. et al. Animal species diversity driven by habitat heterogeneity/ diversity: The importance of keystone structures. Journal of Biogeography., v. 31, p. 79-92, 2004.

WARDLE, D.A. et al. The influence of plant litter diversity on decomposer abundance and diversity. Soil Biology \& Biochemistry, v. 38, p. 1052-1062, 2006. 